\title{
Artigo
}

\section{A insularidade cabo verdiana além da questão geográfica e a emigração como consequência representada na arte}

\author{
The Cape Verdean Insularity beyond the geographic issue and the emigration as a \\ consequence represented in art.
}

DOI: 10.5752/P.1809-6182.2017v14.n1.p68

André Laender Pita ${ }^{1}$

\author{
Recebido em: 17 de agosto de 2016 \\ Aprovado em: 13 de dezembro de 2016
}

\begin{abstract}
RESUMO
A insularidade cabo verdiana é um tema recorrente em estudos relacionados à história, economia e, inclusive, à arte do país. O pequeno Estado africano, resultado de um longo periodo de colonização portuguesa, apresenta características diferenciadas em relação aos outros territórios que tiveram ocupação semelhante e, por isso, o termo insularidade acabou sendo amplamente utilizado como sendo parte da cultura cabo verdiana. Este trabalho faz uma análise da questão insular no Estado de Cabo Verde como um fator de distanciamento físico dos demais Estados, as implicaçóes que o conceito tem além do afastamento territorial e como isso resulta na intensa emigração, fato já característico da população cabo verdiana. Por fim, apresenta representaçóes artísticas da emigração como resultado da insularidade, nomeadamente na obra de Kiki Lima, artista plástico cabo verdiano residente em Portugal.
\end{abstract}

Palavras-chave: Cabo Verde, insularidade, emigração

\section{ABSTRACT}

The Cape Verdean insularity is a recurrent theme in studies related to the history, economy and even the art of the country. The small African State, result of a long period of Portuguese colonization, presents different characteristics in relation to other areas that had similar occupation and therefore the term insularity ended up being widely used as part of the Cape Verdean culture. This work is an analysis of the insular issue in the State of Cape Verde as an issue of physical distance from other States, the implications that the concept has beyond this territorial distance and how it results in intense emigration, a known fact that is a characteristic of the Cape Verdean population. Finally, it features artistic representations of emigration as a result of the insularity, particularly in the work of Kiki Lima, Cape Verdean artist currently residing in Portugal.

Keywords: Cape Verde, insularity, emigration

1. Mestre em Estudos Didáticos Culturais Linguísticos e Literários pela Universidade da Beira Interior. Graduado em Relaçóes Internacionais pela PUC Minas. ORCID: orcid.org/0000-0002-9017-0956. 


\section{Introdução}

Apesar de ser um Estado de território pequeno e população igualmente pequena em relação a diversos Estados, inclusive várias das ex-colônias portuguesas e até mesmo Portugal, Cabo Verde é um objeto de estudo frequente, principalmente em meio aos países de língua portuguesa, por possuir diversas particularidades que o distinguem dos demais países que compartilham o mesmo idioma oficial.

Uma questão curiosamente recorrente e de importância amplamente conhecida é a insularidade como fator intrínseco à identidade cabo verdiana, inclusive representada em diversos tipos de manifestaçôes artísticas, como música, literatura e pintura. Apesar de haver dezenas de outros Estados que compartilham a característica insular de Cabo Verde, este arquipélago localizado próximo à costa africana é alvo de frequentes referências que utilizam a palavra "insular" carregada de diversos significados que compóem parte do que se pode chamar de identidade cabo verdiana.

Observando a relevância do tema na cultura cabo verdiana, é importante frisar que, de acordo com Hall:

As culturas nacionais são compostas não apenas de instituiçôes culturais, mas também de símbolos e representaçôes. Uma cultura nacional é um discurso - um modo de construir sentidos que influencia e organiza tanto nossas açôes quanto a concepção que temos de nós mesmos (veja Penguin dictionary of Sociology: verbete "discourse"). As culturas nacionais, ao produzir sentidos sobre "a naçấo", sentidos com os quais podemos nos identificar, constroem identidades. Esses sentidos estâo contidos nas estórias que são contadas sobre a nação, memórias que conectam seu presente com seu passado e imagens que dela são construídas. Como argumentou Benedict Anderson (1983), a identidade nacional é uma "comunidade imaginada". (HALL, 2005, p. 50).
Levando este conceito em consideraçáo, este trabalho pretende explorar a questão da insularidade cabo verdiana a partir da referência meramente física que a palavra pode fazer, agregando posteriormente as diversas variáveis que enriquecem o termo na cultura cabo verdiana e mostrando como isso resulta na característica emigração praticada pelos habitantes.

Para isso, também é importante reforçar a ideia da correlação entre diáspora e identidade. De acordo com Cancian:

Diáspora significa o espalhamento dos povos, que saem de sua terra de origem para concretizar a vida em outros países ou em outros continentes. Seja de forma forçosa ou por opção própria, os povos que abandonam sua casa jamais se desapegam das origens, e mantém através da tradição a cultura na qual nasceram. Isso se dá pela manutenção da língua, da religiáo, modo de pensar e agir. Mas essa cultura original, no contexto diaspórico, está em constante transformação, de maneira que novos costumes acabam sendo assimilados e interferem náo apenas na identidade pessoal como na identidade coletiva, que por sua vez reflete a identidade cultural de determinado grupo. (CANCIAN, 2016, p. 2).

Por fim, o trabalho apresenta exemplos de como a emigração resultante da insularidade é representada em obras de arte, nomeadamente do artista plástico cabo verdiano Kiki Lima e introduz um conceito de insularidade específico para a realidade do arquipélago.

\section{Breve histórico de Cabo Verde}

Enquanto ex-colônia portuguesa, não é incorreto presumir que muito da história cabo verdiana coincide com a história de outros Estados, principalmente africanos, que também tiveram Portugal como nação colonizadora. No entanto, Cabo Verde apresenta algumas singularidades que não compartilha com as demais ex-colônias: 
Micro-estado insular, independente desde 5 de julho de 1975, com uma área total de $4033 \mathrm{~km}^{2}$ e, conforme dados do censo de 2000, uma população residente de aproximadamente 434 mil indivíduos (à escala africana existem apenas três países mais pequenos em termos de área e de população - as Seychelles, as Comores e São Tomé e Príncipe), situa-se no oceano Atlântico entre os paralelos de $14^{\circ}$ $48^{\prime}$ e $17^{\circ} 12^{\prime}$ Norte e os meridianos de $22^{\circ}$ $41^{\prime}$ e $25^{\circ} 22^{\prime \prime}$ oeste. A menos de $500 \mathrm{~km} \mathrm{da}$ península de Dacar (onde fica o promontório cuja designaçáo lhe deu o nome - Cabo Verde) e a cerca de $2500 \mathrm{~km}$ a sul dos Açores, é constituído por um território fragmentado, disperso por dez ilhas (uma das quais desabitada) e oito ilhéus (citem-se, entre outros, os ilhéus Branco, Raso e os ilhéus Secos). A capital é a cidade da Praia, na ilha de Santiago, e em 2000 contava com cerca de 94000 habitantes. (CRISTÓVÃO, 2005, p. 373).

Em dados mais recentes, podemos perceber que a população cabo verdiana não cresceu muito, conforme afirmado por Ine apud Vieira (2012, p. 26) que a população teria, em 2011, 527.269 pessoas em território nacional, sendo que haveria número muito próximo a esse de emigrantes espalhados por outros países.

Importante ressaltar que "a natureza arquipelágica de algumas regióes insulares traduz-se na fragmentação e dispersão do território, reflectindo-se, muitas vezes, na existência de uma grande diversidade intra-regional" (FERNANDES; SOUZA; FERNANDES, 2016, p. 2381), fator perfeitamente possível de ser observado pelas diferentes ilhas de Cabo Verde.

Além das questóes demográficas, cabe aqui evidenciar também que "A escassez da água tem, historicamente, colocado as maiores dificuldades ao desenvolvimento deste país, provocando as denominadas crises cíclicas, que desde o século XVI até à década de 1940 deram origem a situaçóes de fome e miséria.” (CRISTÓVÃO, 2005, p. 373), o que representa uma questão extremamente delica- da para o crescimento da capacidade econômica de Cabo Verde.

Em termos políticos, pode-se dizer que Cabo Verde se diferencia por não estar incluído nos casos africanos de maior repercussão na mídia internacional, em que são retratadas diversas situações conflituosas. Esta diferença é uma comparação inevitável, pois "todo o processo de construção da identidade nacional cabo-verdiana tem o continente africano como referência, seja para uma afirmação de distanciamento, ou para uma afirmação de proximidade ou de pertencimento" (ANJOS, 2004, p. 273).

Semedo (2016) afirma que o país foi beneficiado por possuir uma classe de burocratas experientes em administração, herança do período colonial que permitiu uma transição política estável com o fim da colonização, garantindo um cenário político relativamente estável que conseguiu algum crescimento e projeção internacional na primeira década do século XXI. Com isso, é possível afirmar que atualmente:

Ao nível da organização política deve-se referir que Cabo Verde é uma República soberana, unitária e democrática, onde vigora o respeito pela pessoa humana e aos Direitos do Homem. E é também um Estado que reconhece, sem qualquer tipo de distinção, a igualdade entre os cidadãos perante a lei. (OLIVEIRA, 2010, p. 70).

Levando esses fatores em consideração, é possível começar a interpretar a questão da insularidade no contexto cabo verdiano. As diferentes referências que a palavra pode fazer e as implicaçóes na realidade local vão construir a perspectiva local do que é a questão insular.

\section{A insularidade enquanto limitação física}

O termo insularidade remete, imediatamente, ao conceito mais básico de ilha, permitindo con- 
cluir que: o que é insular não tem ligação com o continente. Sendo assim, a questáo da insularidade, num primeiro momento, pode parecer algo que está exclusivamente ligado à questáo da geografia física, que é o que este trabalho observa no caso de Cabo Verde. Considerando as limitações físicas do território cabo verdiano, vale enfatizar que "O desenvolvimento depende muito de factores geográficos, sejam eles humanos ou físicos, daí justifica-se uma abordagem aos aspectos Geográficos de Cabo Verde para dar a conhecer, em parte, a realidade cabo-verdiana." (OLIVEIRA, 2010, p. 12).

Como já se sabe, Cabo Verde é um pequeno arquipélago no oceano atlântico relativamente próximo da costa da África. Em determinados aspectos, pode-se dizer que Cabo Verde se afasta das características da África continental mas compartilha particularidades com as demais nações insulares do continente:

À escala do continente a que pertence, Cabo Verde, tal como outros países insulares, apresenta significativa individualidade geográfica, onde cada ilha é um pequeno microcosmos. Desabitadas aquando do seu achamento, as ilhas foram modeladas por cinco séculos de colonização portuguesa que gerou paisagens humanas originais, onde se reflecte o efeito de uma luta constante e tenaz com a natureza saeliana. (CRISTÓVÃO, 2005, p. 373).

No entanto, o posicionamento do arquipélago cabo verdiano apresenta características ainda mais específicas desta pequena nação. Fator que pode, inclusive, colocar o arquipélago em posição estratégica em relação às demais nações do continente:

As vantagens da sua localização numa zona privilegiada da rota de circulaçáo, numa altura em que a navegaçáo à vela explorava a regularidade dos ventos alísios para a conquista de caminhos marítimos para "os mundos cobiçados" justifica a rápida incorporaçấo das ilhas de Cabo Verde no património territorial ibérico como foram agregadas todas as restantes ilhas da Macaronésia. As ilhas então desérticas tornaram-se um lugar geoestratégi- co no âmbito o projecto de expansão europeia e importante escala de navegaçáo entre os continentes Europeu, Africano, Asiático e Americano. (SEMEDO, 2016).

Além do período colonial, a posição das ilhas mostrou-se importante também, durante muito tempo, como apontado por Pereira (2011, p. 23), ao discorrer sobre a conveniência do local em rotas de transporte aéreo. $\mathrm{O}$ arquipélago foi parte fundamental de conexáo e abastecimento de aeronaves que faziam voos entre a Europa e a América do Sul.

Porém, apesar das vantagens competitivas econômicas proporcionadas pela posição geográfica, este mesmo posicionamento traz ao arquipélago grandes desafios devido às condiçôes climáticas, que se traduzem em problemas extremamente difíceis de contornar:

Pela sua posição geográfica, Cabo Verde marca a extremidade ocidental da faixa do Sahel, caracterizada por condiçóes climáticas de aridez e semiaridez, na dependência de fenómenos que acompanham as migraçóes anuais $\mathrm{e}$ seculares da convergência intertropical e seus efeitos desastrosos quando, nos movimentos para o norte, tal faixa pluviogénica da circulação atmosférica não alcança as ilhas. Secas e crises têm sido acontecimentos constantes no arquipélago, constituindo, só por si, os maiores desafios para a população que vive, fundamentalmente, da agricultura pouco diferenciada e de algumas atividades com ela ligadas. Nada pode o engenho humano para alterar tais fenómenos de escala planetária. A virtude está em tirar o melhor partido das particularidades do clima. (ALBUQUERQUE; SANTOS, 1991, p. 1).

Santos (2011, p. 58) afirma que as ilhas possuem atributos especiais que as distinguem dos ambientes não insulares em características, não só físicas e biológicas, como também sociais e econômicas. $\mathrm{O}$ autor defende que a questáo insular é responsável por reflexos na fauna, flora e as atividades humanas, o que resulta em ecossistemas frágeis e vulnerabilidade política e social dos habitantes das 
ilhas. Somadas as características, vão condicionar o desenvolvimento do arquipélago.

Outro ponto importante em relação aos arquipélagos é apresentado por Fernandes, Souza e Fernandes (2016, p. 2389) ao evidenciar que a distância entre as ilhas constitui um problema logístico, o que as torna dependentes de um sistema de transportes eficiente, que por sua vez é de implementação difícil e dispendiosa, pois a transposição das distâncias exige um investimento alto e trabalho intenso.

Paula aponta que "Com relação a Cabo Verde, sabe-se que a privação natural a que sempre estiveram sujeitos seus habitantes acabou por empurrá-los para o exílio físico ou para a evasão, num movimento dialético incapaz de ser satisfeito" (PAULA, 2005, p. 72).

A parte do que já foi apresentado, Sérgio Neto (2008, p. 186) aponta uma relação muito próxima do cabo verdiano com o mar, o que, não só compara o cabo verdiano à tradicional imagem do português, em determinado grau, como também representa o quão presente a questáo da insularidade está na vida dos habitantes das ilhas.

\section{Demais fatores da insularidade que resultam na emigração}

O isolamento geográfico das ilhas já é, por si só, um fator de elevadíssima relevância para a populaçáo local, tanto em questóes econômicas e políticas quanto até mesmo na própria identidade cultural, que passa a contar com esses limitadores físicos para modelar as suas formas de expressão. Desde questóes militares, como aponta Mearsheimer (2001) ao definir o poder parador das águas como uma barreira que dificulta a ação militar entre Estados separados pelo mar até as questôes logísticas apontadas por Fernandes, Souza e Fernandes (2016, p. 2389), como a dificuldade de se estabelecer um sistema eficiente de transportes nas ilhas, a ausência de fronteiras terrestres por si só é uma questão extremamente delicada. Vale ressaltar que Mearsheimer era bem específico ao definir o seu conceito em relação aos conflitos militares, o que não se aplica diretamente ao caso cabo verdiano, mas ainda assim serve para demonstrar a força da barreira física imposta pelo mar. No entanto, a insularidade cabo verdiana náo pode ficar restrita a isso, há ainda outras variáveis que devem ser consideradas. Monteiro da Silva "defende que o fenómeno da insularidade é muito mais do que o mero conceito físico" (DA SILVA apud DELGADO, 2009, p. 168).

Um dos principais fatores que podem ser mostrados aqui ainda diz respeito à geografia física, mas já não está vinculado necessariamente à questão insular do país. As condiçóes climáticas de Cabo Verde são delicadas e, curiosamente, percebe-se aqui um fator relacionado à proximidade do arquipélago com o continente. Cristóvão (2005, p. 376) apresenta a recorrência do vento vindo do deserto do Saara para o arquipélago, quente e seco, conhecido por registrar quebras drásticas na umidade do ar e trazer consequências na produtividade das colheitas e na saúde da população.

Além do clima, pode-se mencionar também a questão da pobreza do terreno cabo verdiano, que prejudica enormemente a produção nacional, trazendo entraves ao desenvolvimento da economia local:

$\mathrm{Na}$ solidez dos edifícios vulcânicos, uns mais conservados, como o Fogo, ou mais alcantilados, como Santo Antáo e Santiago, outros muito erodidos, como o Sal, Boavista e Maio, não há riquezas minerais de valor económico, nem sólidas, nem líquidas, nem gasosas. Quanto a fontes de energia, apenas restam as do Sol, dos ventos e das águas do mar. Salvo o sal, sobretudo no Sal e na Boavista, e algumas pozolanas em Santo Antáo, por todo o lado dominam as rochas vulcânicas, com predomínio das basálticas; os poucos retalhos de for- 
mações sedimentares são de valor nulo. (ALBUQUERQUE; SANTOS, 1991, p. 1-2).

Por todos estes condicionantes naturais ao desenvolvimento local, essa falta de recursos tão expressiva, Alcobia (2010, p. 46) afirma que Cabo Verde nunca teria sido foco de interesse para a exploração por parte dos poderes da política colonial. Está, é claro, em localização estratégica para as rotas portuguesas, mas o clima não favorecia uma ocupação mais intensa do território.

Andrade, citado por Vieira (2012, p. 28) expõe todo o histórico de exploração sofrido pelas ilhas durante a colonização, que resultaram numa população despreparada e desamparada, sem projetos que pudessem trazer desenvolvimento, infraestrutura precária para o atendimento à população, nomeadamente os cuidados com a saúde, e taxa de desemprego elevada.

A partir disso é possível perceber que há razóes suficientes que motivem a população cabo verdiana a buscar uma melhora na qualidade de vida em outros lugares, pois na terra natal as condições são realmente adversas e não oferecem grandes oportunidades para os que ali vivem. Isso ilustra porque a emigração é uma constante tão intensa na vida do cabo verdiano:

Esta atracção pela diáspora deve-se, sobretudo, à posição geográfica do arquipélago de Cabo Verde, que proporciona uma irregular e às vezes nula pluviosidade, a qual aliada à escassez de bons solos não possibilita uma produção agrícola em moldes pelo menos de auto-abastecimento. Em Cabo Verde, há ainda um débil investimento, salários baixos, deficiente orientaçáo dos recursos existentes, insuficiente assistência social e fraco desenvolvimento industrial. Talvez sejam estes motivos aliados a razóes históricas e a causas socioeconómicas que nos fazem compreender porque esta gente se espalhou pelo mundo. Saint Maurice refere que a "emigração desde cedo se mostrou como $<<a$ janela alternativa à porta que Deus fechou>>" (1997: 44) (ALCOBIA, 2010, p. 50).
Cabe aqui apontar que, embora a autora ressalte a questão geográfica como fator principal que teria impulsionado a emigração, a posição geográfica por ela mencionada não se restringe ao fato de ser uma nação insular, mas sim dos demais condicionantes aos quais o arquipélago está submetido:

A história da emigração cabo-verdiana é relativamente longa. Ela faz parte da própria história do povo cabo-verdiano. Góis menciona (2006: 23), que "pode afirmar-se que o cabo-verdiano já nasceu (e) migrante, ou, dito de outro modo, que a emigração é um dos fenómenos mais antigos e estáveis da sociedade cabo-verdiana, antecedendo em muitas décadas a independência do país que ocorreu em 1975. Neste sentido, Cabo Verde é um exemplo, talvez único, de um Estado que nasce já transnacionalizado". Como salienta Lobo (2007: 171) na vida de qualquer cabo-verdiano é inevitável a ideia de emigração. (LOPES, 2011, p. 30).

Cristóvão (2005, p. 384) aponta os Estados Unidos como um dos destinos principais dos emigrantes cabo verdianos, mas também mostra, ao longo do tempo, outros destinos também recorrentes entre os cabo verdianos. Interessante mencionar que o autor cita a outra ex-colônia portuguesa, São Tomé e Príncipe, que também constitui um Estado insular, representando assim um destino discrepante da diáspora cabo verdiana.

Mesmo com a diáspora tendo tanta expressividade na história e cultura local, é válido mencionar que o patriotismo também é forte para o cabo verdiano:

Para este povo, o desejo e a necessidade de partir é forte. Desejo este alimentado pelos que regressam, pelos marinheiros, pelos emigrantes, pelas cartas que vêm de longe, pelo sentimento quase obsessivo de lugares melhores. Contudo, o cabo-verdiano, esteja onde estiver, nunca renuncia à sua terra, daí a ideia fixa de que há-de voltar um dia, como se o regresso fosse um compromisso. (ALCOBIA, 2010, p. 50).

Um estudo feito por Lopes (2011, p. 62) sobre a emigração de mães cabo verdianas concluiu 
que a principal razão para deixar o país era o fator econômico. A pobreza e precariedade de Cabo Verde fez com que essas mulheres emigrassem em busca de oportunidades de melhora de condiçóes de vida, não tendo feito menção específica à característica insular do país.

\section{Representações da insularidade na arte}

A expressão cultural de um povo se dá de diversas maneiras. Desde questóes comportamentais até a língua ou a gastronomia, é possível observar como os costumes se manifestam e refletem características importantes da população de um determinado local. Na questão cabo verdiana não é diferente. Falantes de crioulos de base portuguesa, os cabo verdianos possuem uma identidade cultural forte, produto de todo o seu histórico de colonização, exploração e emigração. E, apesar das várias maneiras de expressão, a arte, em suas diversas formas, continua sendo o mais explícito modo de demonstração:

A representação inclui as práticas de significação e os sistemas simbólicos por meio dos quais os significados são produzidos, posicionando-nos como sujeito. É por meio dos significados produzidos pelas representaçóes que damos sentido à nossa experiência e àquilo que somos. Podemos inclusive sugerir que esses sistemas simbólicos tornam possível aquilo que somos e aquilo no qual podemos nos tornar. A representação, compreendida como um processo cultural, estabelece identidades individuais e coletivas e os sistemas simbólicos nos quais ela se baseia fornecem possíveis respostas às questóes: Quem sou eu? $\mathrm{O}$ que eu poderia ser? Quem eu quero ser? Os discursos e os sistemas de representação constroem os lugares a partir dos quais os indivíduos podem se posicionar e a partir dos quais podem falar. (WOODWARD, 2015, p. 17-18).

Com isso podemos perceber na arte, a força que tem para o cabo verdiano a questão da insularidade e da emigração que decorre disso. "Para além da dimensão social, cultural e política que a insularidade assume perante os habitantes das ilhas do Arquipélago, demonstra, por outro lado, como é que ela contribui para a afirmação da identidade seja ela regional ou nacional. " (DELGADO, 2009, p. 169-170).

Alcobia (2010, p. 50) descreve o cabo verdiano como aquele que vive em constante dicotomia por estar dividido entre o país de origem e aquele para onde emigra enquanto Stoenesco (2016, p. 56) coloca a insularidade entre os temas mais recorrentes da poesia cabo verdiana.

Considerando essas características da história, da identidade e da arte cabo verdiana, podemos observar algumas obras do artista Kiki Lima. Mais especificamente, obras em que fica explícita a questão da emigração evidenciando a insularidade do país. Oliveira Júnior afirma que "O emigrante e o mar são temas recorrentes em todas as expressōes artísticas de Cabo Verde, não só na literária. A pintura de Kiki Lima não seria exceção(...). ” (OLIVEIRA JÚNIOR, 2010, p. 155).

A obra Partida (LIMA apud OLIVEIRA JÚNIOR, 2010, p. 156) não diz respeito à insularidade, pelo menos não de forma direta, mas pode-se considerar uma menção indireta dado o quão explícita está a temática da imigração, na triste cena em que um pai se despede da família, que constitui em quatro filhos mais a mulher grávida. Sinais de vegetação na obra e a simplicidade das vestimentas dos que ficam demonstram o quão pobre é o local que ele está prestes a abandonar, assim como a roupa mais sofisticada do pai sugere que está a caminho de algo melhor, mais promissor do que a terra que fica. Expressões tristes evidenciam o sentimento dos que se despedem e a saudade que os vai perseguir enquanto estiverem separados, não surpreendente, pelo mar. A cor azul, presente na roupa do pai e no avental da mãe, pode sugerir ainda uma relação entre o que vai, os que ficam, e o mar que os separa. 


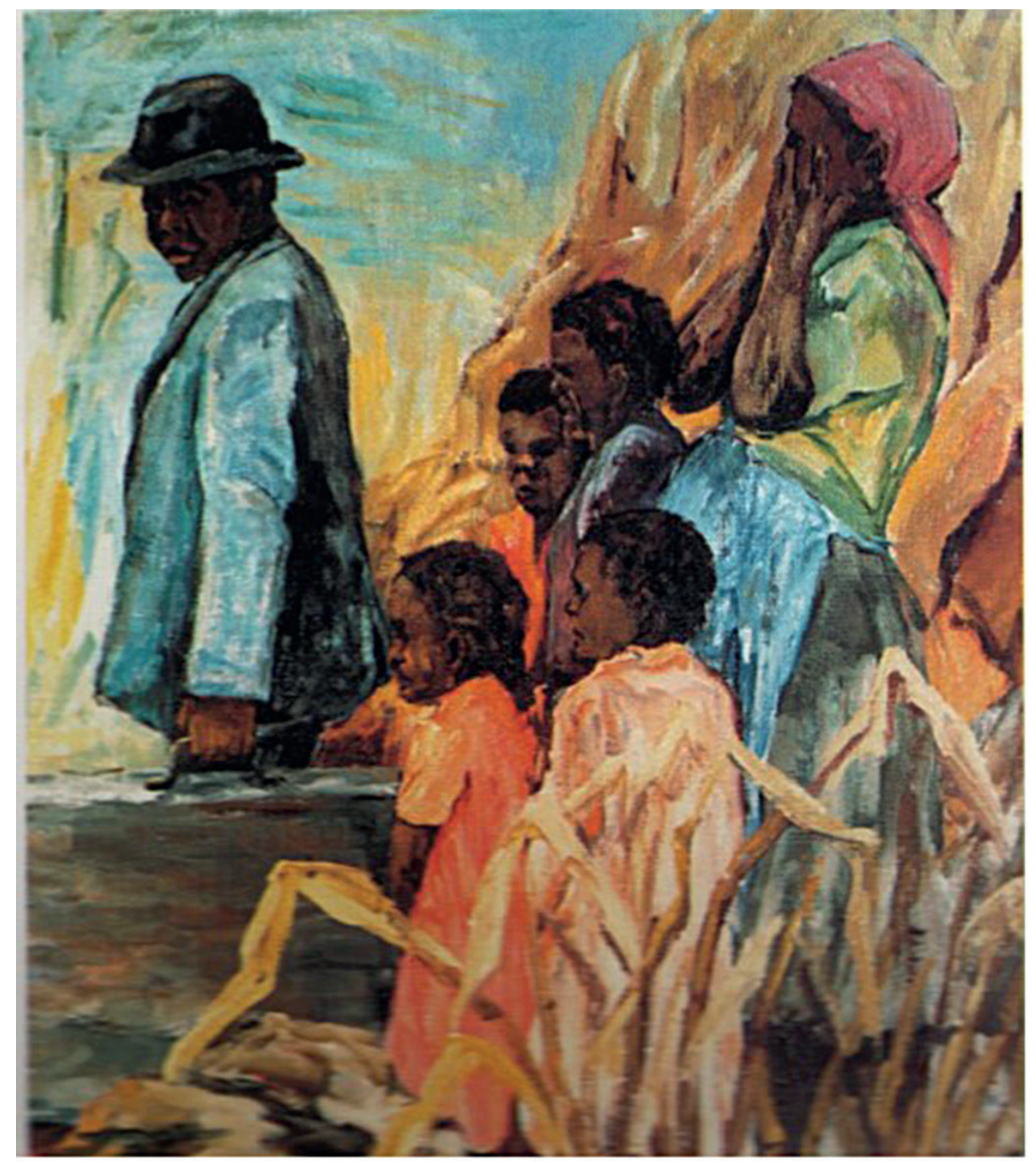

Figura 1: Kiki Lima, Portida

Fonte: Lima apud Oliveira Júnior (2010, p. 156)

Em outra obra mais recente do artista, Bagagem de mão (LIMA, 2011), mais uma vez a insularidade não é explícita. A obra representa uma mulher, também vestida de forma simples, tem dificuldade em carregar a sua bagagem. O volume da bagagem fica evidenciado não só pela representação, mas pela contradição com o título 'Bagagem de mão'. A quantidade de bagagem que a mulher tem que carregar, associada à ausência de pessoas conhecidas que a possam ajudar permite deduzir que está em um lugar que náo conhece, sendo assim, mais uma cabo verdiana que teria ido tentar uma vida melhor no exterior. Com tantas coisas para carregar, claramente saiu de casa sem saber quando volta e, a distância (o mar) que a separa de casa dificulta idas e vindas, sendo que teve que levar tudo de uma vez para poder ficar fora de casa o tempo que precisar. Curioso observar mais uma vez a forte presença da cor azul na pintura, que pode ser uma referência ao mar. Mais curioso ainda é ver que a bagagem está pintada de azul enquanto a mulher não. No entanto, ela está posicionada no centro, rodeada de malas azuis, numa posição em que parece estar ilhada, isolada do contato direto com tudo pois ao seu redor, tudo tem o azul do mar. Outro ponto curioso é o fato de ser uma mulher representada na obra e não um homem. Uma vez que a emigração é mais comum para os homens, a mulher representa uma situação atípica de maneira geral, mas não tão rara assim para o caso cabo verdiano, pois condiz assim com as já mencionadas mães de Cabo Verde que emigraram para Portugal. 


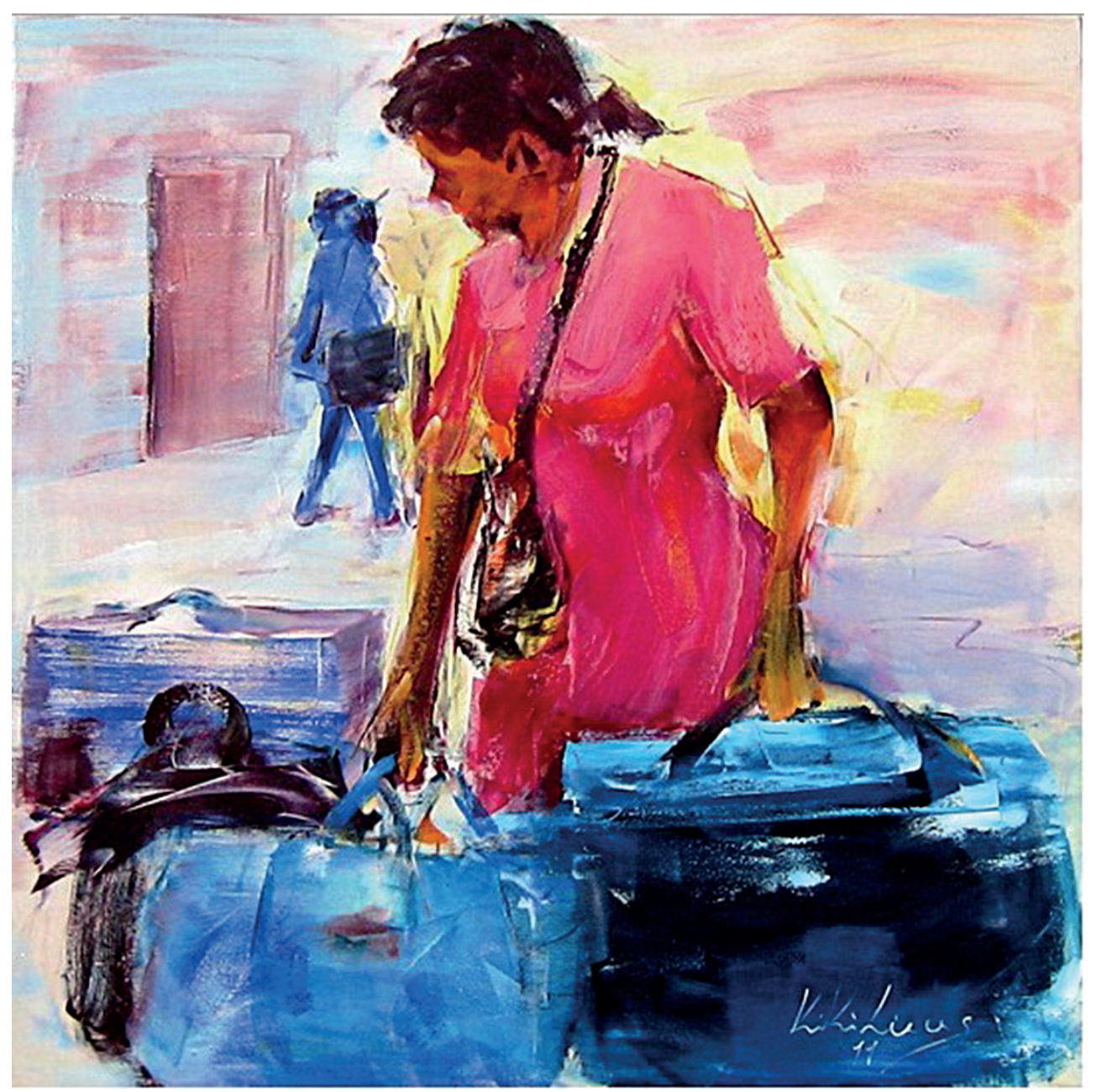

Figura 2: Kiki Lima, Bagagem de mão

Fonte: Lima (2011)

Já observando a obra Mar de Sodade (LIMA apud OLIVEIRA JÚNIOR, 2010, p. 158), é possível ver claramente como estâo representadas as questôes do mar, da imigração e como a questâo da insularidade se faz presente. A obra retrata uma mulher sentada em uma pedra de frente para o mar. Apesar de estar de costas, a mulher, que veste roupas muito simples, tem uma postura triste diante da imensidão do mar. Conhecendo a história cabo verdiana, deduz-se que contempla o oceano por causa de parentes ou amigos que deixaram a terra em busca de condiçóes melhores no exterior. $\mathrm{O}$ mar representa o isolamento do arquipélago cabo verdiano e a dificuldade de o transpor é uma alusão à complicada situação do país e à comparável dificuldade de conseguir uma vida melhor. Enquanto isso, também é possível perceber que a mulher senta sobre uma pedra. A única representação do terreno na obra é a pedra marrom sob a personagem, uma possível referência à aridez e pobreza da terra, que dificulta qualquer tentativa de progresso, colocando os seus filhos na difícil situação entre ficar e tentar prosperar em condiçôes tấo adversas ou criar coragem para transpor a imensidão do mar em busca de uma vida, ainda que mais confortável, longe da árida terra natal, à qual são tão apegados. A obra coloca o expectador atrás da mulher que está representada para que possa compartilhar com a personagem o ponto de vista do mar. 


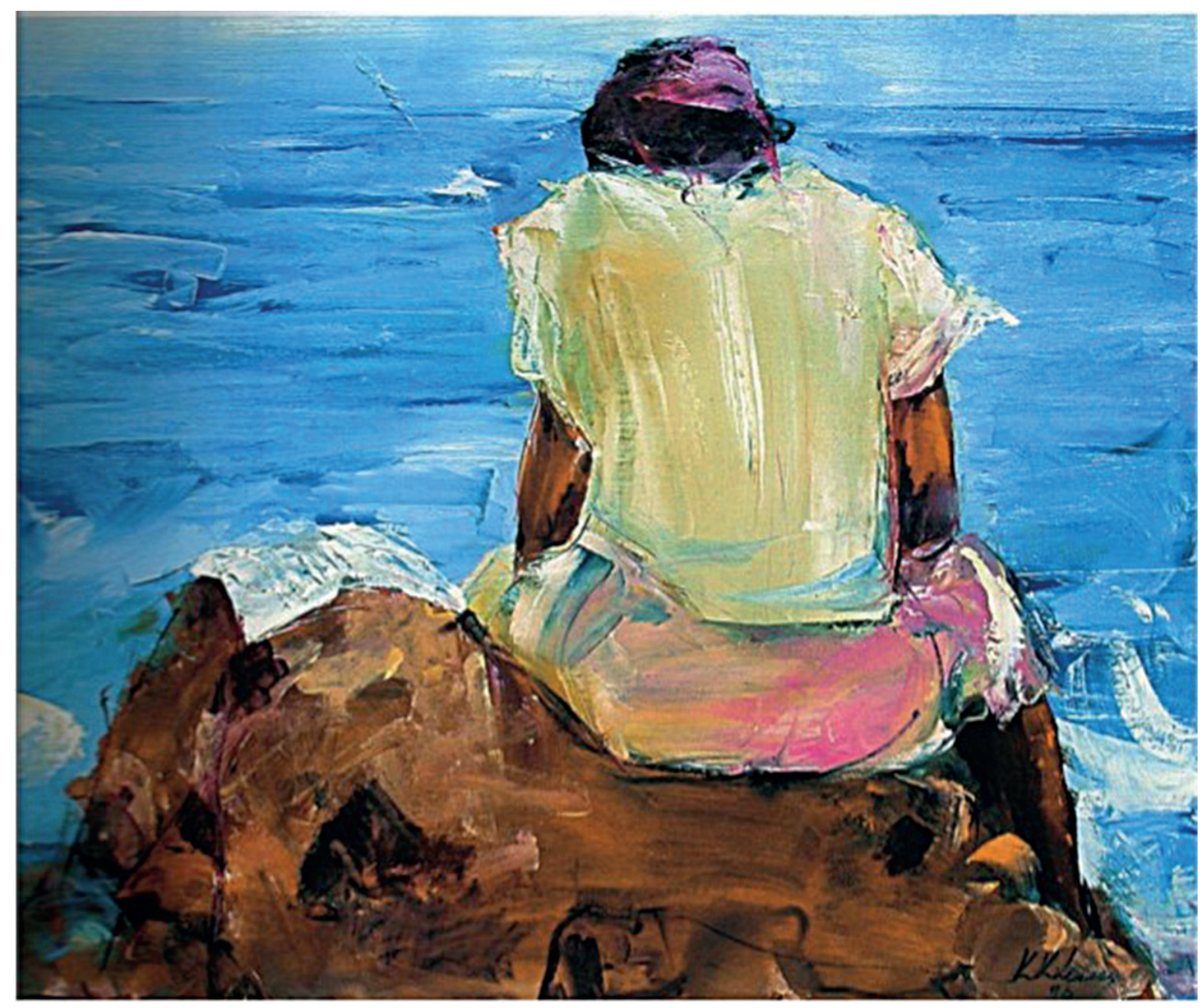

Figura 3: Kiki Lima, Mar de Sodade

Fonte: Lima apud Oliveira Júnior (2010, p. 158)

Sérgio Neto (2008) cita outro tipo de arte que demonstra o mesmo sentimento presente no cabo verdiano:

Gente sofredora, pobre, que trabalha o solo ingrato; povo de pescadores marinheiros que emigra para voltar, num amor entranhado à terra-mãe; gente que traduz o seu sentimento artístico na morna - canção dolente, canção de amor, canção de embalar, que é ao mesmo tempo um queixume delicado contra o destino agressivo e a síntese do que lhes inspira o amor, a saudade e a natureza. (NETO, 2008, p. 187)

Para complementar, Santos (1989, p. 59) vê na insularidade "o sentimento de solidão, de nostalgia, que o ilhéu experimenta face ao isolamento e aos limites da fronteira líquida que o separam do resto do mundo, criando-lhe um estado de angús- tia e de ansiedade que o levam a sonhar com outros horizontes para lá do mar". A fronteira líquida permanece sob duas perspectivas: a distância entre quem vai e quem fica e ao mesmo tempo uma ligação entre ambos. Uma vez que o mar, pelo menos numa perspectiva imaginária, representa a distância entre as duas partes, ele também não deixa de estar presente nas duas ao mesmo tempo, trazendo uma espécie de união entre aqueles que não estão juntos.

\section{Conclusão}

A partir desta investigação, podemos perceber que a questâo da insularidade cabo verdiana claramente não se restringe ao isolamento físico causado pela ausência de fronteiras terrestres com outras naçôes. A distância física entre as ilhas e o continente preenchida pelo mar realmente não facilita o desenvolvimento da 
naçáo por apresentar complicaçóes logísticas difíceis e caras de resolver. No entanto, a insularidade identitária do cabo verdiano vai muito além dos mais de quatrocentos quilômetros que os separam do continente.

Cabo Verde foi uma colônia duramente explorada durante muitos anos e não teve uma boa preparação que proporcionasse uma autonomia confortável e promissora para os habitantes que ali ficaram após a independência do arquipélago. Um terreno extremamente pobre associado ao clima desfavorável à exploração e a um tipo de colonização que não se preocupou em desenvolver a região fez com que o arquipélago de posição estratégica ficasse vitimado por estar numa terra de tão poucos recursos com uma população tão despreparada para administrar as suas próprias ilhas.

Mesmo a estabilidade política do período de transição entre o domínio colonial e o Estado independente não foi suficiente para permitir que Cabo Verde despontasse economicamente e proporcionasse uma qualidade de vida melhor para os seus habitantes, o que fez com que a tão falada insularidade cabo verdiana fosse, na verdade, o resultado de todo esse histórico agregado, e náo o fato isolado de estarem em ilhas.

Há dezenas de outros estados insulares distribuídos pelos oceanos do planeta, mas não é tão comum fazer referência à insularidade do mesmo modo. Caso fosse uma questáo meramente física, a emigração cabo verdiana não teria tido como destino um outro Estado insular: São Tomé e Príncipe. Ainda que tenha sido algo pontual na história.

Por fim, o que se pode concluir é que a insularidade cabo verdiana não é resultado das limitaçôes físicas do terreno do país, mas sim potencializada por isso. $\mathrm{O}$ isolamento foi um problema muito maior no passado do que é hoje, uma vez que a transposição das distâncias físicas atualmente é algo mais caro que difícil de se conseguir. A história repleta de adversidades que as ilhas protagonizaram foi responsável por tornar um terreno pobre de clima desfavorável em um país sem condições de se desenvolver economicamente por falta de planejamento, o que resulta em uma população que se sente isolada do resto do mundo pela pobreza e dá a isso o nome de insularidade. Sendo assim, a arte cabo verdiana se apropriou do tema da insularidade para representar todo esse mosaico de contribuintes históricos que resultou no povo que se sente isolado na ilha que ama e apesar de amar a pátria, emigra.

\section{Referências}

ALBUQUERQUE, Luís de; SANTOS, Maria Emília Madeira (Coord.). História Geral de Cabo Verde. Lisboa: Instituto de Investigação Científica Tropical, 1991.

ALCOBIA, Alice. Papia, Lé y Skrebe na Skóla Kauberdianu: A Emergência de Práticas Identitárias. Lisboa: Fundação Calouste Gulbenkian, 2010. 544 p.

ANJOS, José Carlos Gomes dos. A condição de mediador político-culturalem CaboVerde: intelectuaisediferentesversôesda identidade nacional. Etnográfica, v. VIII (2), 2004.

CANCIAN, Juliana Raguzzoni. O contexto da diáspora na construçáo da identidade cultural: a experiência do personagem José Viana, do romance Sem Nome, de Helder Macedo. Disponível em: <http://www.bocc.ubi.pt/pag/cancian-juliana-contexto-da-diaspora.pdf>. Acesso em: 25 nov. 2016.

CRISTÓVÃO, Fernando (Org.). Dicionário Temático da Lusofonia. Lisboa: Texto Editores, 2005. 975 p.

DELGADO, Carlos Alberto. Crioulos de Base Portuguesa como factores de identidades em África: $\mathrm{O}$ caso de Cabo Verde. 2009. 481 f. Tese (Doutorado) - Curso de Letras, Universidade da Beira Interior, Covilhã, 2009.

FERNANDES, Francisco; SOUZA, Joáo Figueira de; FERNANDES, André. Os Efeitos das Infra-estruturas Rodoviárias no Ordenamento e Desenvolvimento do Território: o caso da Ilha de Santiago, Cabo Verde. 2009. Disponível em: <http://www.apdr.pt/congresso/2009/pdf/Sessão 24/88A. pdf $>$. Acesso em: 11 maio 2016.

HALL, Stuart. A Identidade Cultural da Pós Modernidade. 10. ed. Rio de Janeiro: Dp\&a, 2005.

LIMA, Kiki. Bagagem de máo. 2011. Disponível em: <http:// allartsgallery.com/pt-PT/quadros/1358-bagagem-de-mao?artist_id=126-kiki-lima\&page=2>. Acesso em: 19 maio 2016. LOPES, Carla Suzana Silva. Mulheres Imigrantes Em Portugal: Vivências e Percursos Migratórios das Mães Solteiras Cabo-Verdianas. 2011. 175 f. Dissertação (Mestrado) - Curso de Sociologia, Universidade da Beira Interior, Covilhă, 2011. 
MEARSHEIMER, John. The Tragedy of Great Power Politics. Nova Iorque: W. W. Norton \& Company, 2001.

NETO, Sérgio. Insularidade Idiossincrasias e Imaginação: Representaçóes de Cabo Verde no Pensamento Colonial Português. In: TORGAL, Luís Reis; PIMENTA, Fernando Tavares; SOUSA, Julião Soares (Org.). Comunidades Imaginadas: Nação e Nacionalismos em África. Coimbra: Imprensa da Universidade de Coimbra, 2008. p. 181-192.

OLIVEIRA JÚNIOR, José Leite de. Imagens Poético-Pictóricas da Emigração em Cabo Verde. Graphos, João Pessoa, v. 12, n. 2, p.151-160, dez. 2010.

OLIVEIRA, Bruno. O Desenvolvimento de Cabo Verde: Abordagem ao Mercado de Tradução. 2010. 70 f. Dissertação (Mestrado) - Curso de Tradução e Interpretação Especializadas, Instituto Superior de Contabilidade e Administraçáo do Porto, Porto, 2010.

PAULA, Júlio Cesar Machado de. Manuel Bandeira e Claridade: confluências literárias entre o modernismo brasileiro e o cabo-verdiano. Tese de doutorado. São Paulo: Faculdade de Filosofia, Letras e Ciências Humanas da Universidade de São Paulo, 2005.

PEREIRA, Daniel. Das relaçôes históricas Cabo Verde-Brasil. Brasília: FUNAG. 2011.

SANTOS, Aquiles Celestino Vieira Almada e. A insularidade e suas condicionantes econômicas: o caso dos pequenos estados insulares em desenvolvimento. 2011. $411 \mathrm{f}$. Tese (Doutorado) - Curso de Geografia, Instituto de Geografia e Ordenamento do Território, Universidade de Lisboa, Lisboa, 2011.

SANTOS, Elsa Rodrigues dos. As Máscaras poéticas de Jorge Barbosa e a Mundividência Cabo-Verdiana. Lisboa: Caminho, 1989.

SEMEDO, José Maria. A Especificidade de um Estado Insular e diasporizado. ESTADO NAÇÃO E OS DESAFIOS DA INTEGRAÇÃO REGIONAL: O CASO DE CABO VERDE. Disponível em: <http://portal.unesco.org/shs/fr/files/10991/11840743421j_semedo.pdf/j_semedo.pdf>. Acesso em: 12 maio 2016.

STOENESCO, Dominique. Na morte de Ovídio Martins: Poeta e militante cabo-verdiano. 1999. Disponível em: <http://www.revues-plurielles.org/_uploads/pdf/17_6_13. pdf>. Acesso em: 15 maio 2016.

VIEIRA, Adelina. Política Externa Contemporânea de Cabo Verde: a aposta na política externa como motor de desenvolvimento. 2012. 95 f. Dissertação (Mestrado) - Curso de Relaçóes Internacionais, Universidade da Beira Interior, Covilhã, 2012.

WOODWARD, Kathryn. IDENTIDADE E DIFERENÇA: UMA INTRODUÇÃO TEÓRICA E CONCEITUAL. In: SILVA, Tomaz Tadeu da (Org.). Identidade e Diferença: A Perspectiva dos Estudos Culturais. 12. ed. Rio de Janeiro: Vozes, s/d. p. 7-68. Disponível em: <https://xa.yimg.com/kq/ groups/18474914/1440030907/name/Identidade+e+Diferença.pdf>. Acesso em: 25 dez. 2015. 